\title{
Exilados brasileiros nos países do Prata: mediações e luta antifascista (1933-1939)
}

\author{
Brazilian exiles in Prata countries: \\ mediations and antifascist struggle (1933-1939)
}

Ângela Meirelles de Oliveira ${ }^{1}$

Resumo $\mathrm{O}$ artigo recupera as trajetórias políticas dos intelectuais brasileiros José Barboza Mello e Pedro Mota Lima, que estiveram exilados no Uruguai e na Argentina após a perseguição sofrida por conta dos movimentos comunistas de 1935, no Brasil. No combate aos governos autoritários e à expansão do fascismo, estes exilados atuaram ativamente na imprensa das organizações antifascistas do Uruguai e da Argentina e serviram de mediadores culturais e políticos da situação brasileira, especialmente com relação à Aliança Nacional Libertadora (ANL) e seu líder, Luiz Carlos Prestes. Buscamos comprovar como a experiência do exílio pode ser prolífica na promoção de mediações políticas e dos intercâmbios culturais no contexto da luta antifascista.

Palavras-chave exílio; intelectuais; antifascismo.

Abstract This article recovers the political trajectories of the Brazilian intellectuals José Barboza Mello and Pedro Mota Lima who were exiled in Uruguay and Argentina after the persecution due to the communist movements of 1935 in Brazil. In the fight against authoritarian governments and also against the expansion of fascism, those exiled worked actively in the press of the anti-fascist organizations in these countries and served as cultural mediators of the Brazilian political situation, especially related to Aliança Nacional Libertadora (ANL) and its leader Luiz Carlos Prestes. We aim to demonstrate how the experience of exile can be prolific in promoting political mediation and cultural exchange in the context of anti-fascist struggle.

Keywords Exile; Intellectuals; Anti-fascism.

Artigo recebido em: 31/07/2015

Artigo aprovado para publicação em: 15/12/2015

\footnotetext{
${ }^{1}$ Doutora em História Social pela USP, pesquisadora do Laboratório de Estudos de História das Américas (LEHA - USP). Email: angelamo@usp.br.
}

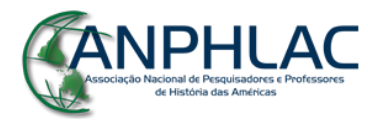

Revista Eletrônica da ANPHLAC, ISSN 1679-1061, №. 19, p. 25-42, jul./dez., 2015. http://revista.anphlac.org.br 


\section{Introdução}

O caráter transnacional da luta antifascista nos anos 1930 se devia a múltiplos fatores: a ampla circulação de ideias pela imprensa, a mobilização internacional dos intelectuais, ao papel da Internacional Comunista (IC) e também ao exílio. Neste artigo, buscaremos demonstrar como o exílio teve um papel fundamental para a circulação de ideias no âmbito da luta antifascista nos países do Cone Sul, especialmente o exílio de intelectuais e militantes brasileiros no Uruguai e na Argentina, sobretudo após os movimentos militares de 1935.

No Cone Sul, as respostas políticas à crise econômica de 1929 foram, em sua maioria, a ascensão de governos conservadores por meio de golpes de Estado; no caso da Argentina, o golpe do Gal. José Félix Uriburu (1930) e na sequência a eleição fraudulenta de Augustín P. Justo (1931), no Uruguai o golpe de Estado de Gabriel Terra (1933) e no Brasil a ascensão de Getúlio Vargas ao poder (1930), com um longo governo com diferentes facetas. A turbulência política nestes países fez com que se intensificasse o número de deslocados que buscavam refúgio em outras nações; grande parte destes deslocados eram militantes e/ou intelectuais, que mantinham sua atividade política e cultural nos países que os abrigavam.

Este artigo se debruçará especificamente sobre a atividade político-cultural de dois intelectuais militantes brasileiros (José Barboza Mello e Pedro Mota Lima), que se exilaram no Uruguai e na Argentina nos anos 30, fazendo, no entanto, rápida referência aos exilados argentinos e uruguaios que chegaram ao Brasil nesta década.

Consideramos que o exilado atuou na condição de sujeito em transição entre dois espaços (OLIVEIRA apud ROLLEMBERG, 1999, p. 29), desempenhando um papel muito importante: dar continuidade à resistência em relação ao avanço do fascismo. Em vista disso, é possível afirmar que a dimensão transnacional dos exilados os torna "vetores fundamentais de mobilização coletiva nos vários domínios e esferas nas quais eles foram ativos." (SZNAJDER; RONIGER, 2009, p. 194). Veremos que os exilados brasileiros nos países do Prata foram mediadores da situação política brasileira frente às

\section{GANPHLAC}

Revista Eletrônica da ANPHLAC, ISSN 1679-1061, №. 19, p. 25-42, jul./dez., 2015. http://revista.anphlac.org.br 
organizações antifascistas do Uruguai e da Argentina. Além disso, eles mantiveram, no exterior, uma ativa militância antifascista já que o Brasil havia perdido seu já reduzido espaço de liberdade de expressão por conta das perseguições policiais desencadeadas pelos movimentos militares de 1935 e, posteriormente, pelo golpe do Estado Novo, em 1937.

Desde a ascensão de Adolf Hitler ao poder em 1933, mas especialmente a partir do ano de 1935, diversas associações de intelectuais foram criadas no Brasil, Argentina e Uruguai. Animadas pelas experiências francesas de apoio à Frente Popular², as organizações previam, sob o mote da defesa da cultura, promover ações de contrapropaganda frente à ascensão do fascismo e do autoritarismo e, ao mesmo tempo, dinamizar os espaços culturais e artísticos dos países sede (OLIVEIRA, 2013). Na Argentina, em julho de 1935, foi criada a Agrupación de Intelectuales, Artistas, Periodistas y Escritores (AIAPE) ${ }^{3}$; pouco mais de um ano depois os intelectuais uruguaios criaram uma organização homônima. Já no Brasil, em 1935, surgiram o Clube de Cultura Moderna (CCM) e o Centro de Defesa da Cultura Popular (CDCP), ligados à Aliança Nacional Libertadora (ANL); tais agrupações tiveram vida curta, devido à intensa repressão policial decorrente dos movimentos de 1935.

Todas as organizações antifascistas citadas acima criaram revistas ou jornais por meio dos quais disseminavam suas ideias, promoviam debates políticos e culturais e divulgavam literatura, artes plásticas e outras formas de expressão artística. A imprensa foi o principal meio de circulação de ideias entre as associações antifascistas do Cone Sul, servindo tanto ao intercâmbio cultural como ao enriquecimento dos debates intelectuais (OLIVEIRA, 2015). Além dos periódicos, outros impressos serviam ao mesmo propósito, como a publicação de livros, tradução de obras e também a circulação de correspondências.

\footnotetext{
${ }^{2}$ A Frente Popular foi uma estratégia política de combate ao fascismo articulada a partir da Internacional Comunista (IC) que visava a criação de uma coalizão de forças de esquerda para combater um inimigo comum. Para tal, a IC aceitou a possibilidade de formação de alianças políticas com outros partidos (oficialmente a partir do VII Congresso da Internacional Comunista, em 1935) e passou a amenizar o tom sectário em relação às outras forças de esquerda. Nos países em foco neste artigo, houve tentativas de articulação de Frentes Populares que, por diferentes motivos, não foram bem sucedidas.

${ }^{3}$ Outra associação antifascista foi criada na Argentina nos anos 40, de cunho liberal e pró-aliados na $2^{\mathrm{a}}$ GM: a Acción Argentina, que acabou por aglutinar intelectuais que se identificavam com essa tendência.
}

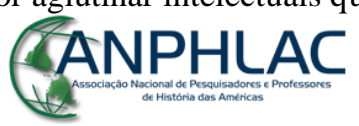

Revista Eletrônica da ANPHLAC, ISSN 1679-1061, №. 19, p. 25-42, jul./dez., 2015. http://revista.anphlac.org.br 
Boa parte destas atividades de imprensa era monitorada pela polícia política brasileira. Os relatórios policiais mostram o minucioso acompanhamento dos passos da intelectualidade uruguaia e argentina, e o envio sistemático de pequenas notas à polícia política do Rio Grande do Sul e do Rio de Janeiro. O prontuário da Delegacia Especial de Segurança Política e Social (DESPS) oferece importantes pistas para se reconstituir os intercâmbios entre os intelectuais brasileiros, argentinos e uruguaios.

O intenso trânsito de jornais e de pessoas nas fronteiras do sul do Brasil era a grande preocupação deste órgão da repressão. Montevidéu era considerada a "capital do bolchevismo na América do Sul" (DESPS, s.d.a., p. 13), fato que tornava urgente medidas para controlar as fronteiras.

Com esse propósito, os policiais elaboraram um relatório, composto por mais de mil nomes, alguns acrescidos de fotografias, que oferecia um retrato detalhado da oposição no Uruguai e das ligações com os militantes brasileiros e argentinos (DESPS, s.d.a., p. 13). Tal documento, apesar de precioso, deve ser analisado criticamente para que não se incorpore o "discurso da ordem" (CARNEIRO, 2006, p. 155) à reconstrução histórica destes contatos, já que as polícias políticas consideravam comunistas qualquer um que se opusesse à conjuntura política do momento. ${ }^{4}$

É importante ressaltar que a luta antifascista foi um fenômeno político e cultural que envolveu atores de tendências ideológicas diversas (GROPPO, 2007, p. 96). A historiografia mais recente se dedica a matizar o peso da "influência comunista" na luta antifascista, dando espaço para outras tendências que têm tido seu papel ignorado ou considerado insignificante. (GROPPO, 2007; TERONI; KLEIN, 2005)

Neste artigo, a reconstituição da circulação de pessoas e ideias antifascistas entre Brasil e os países do Prata ficará restrita aos militantes da ANL em diálogo com as AIAPEs, ainda que eventualmente uma ou outra ligação seja apontada. A partir deste recorte, destaca-se a predominância de um fluxo de pessoas, partindo do Brasil em direção à Argentina e Uruguai, ocorrido devido ao peculiar desfecho da ANL, que forçou muitos militantes, comunistas ou não, a se exilarem nos países vizinhos. Na direção contrária, os intercâmbios foram escassos e pontuais, mas ainda assim importantes.

\footnotetext{
${ }^{4}$ Um exemplo disto é a presença, nesta lista de comunistas, do militante nacionalista uruguaio (do Partido Blanco) Basílio Muñoz, um ferrenho opositor da ditadura de Gabriel Terra, líder do movimento armado de janeiro de 1935 no Uruguai e que, definitivamente, não era comunista.
} 
A vinda de Raúl González Tuñón ao Brasil em 1931, como correspondente do jornal argentino Crítica, foi decisiva para o estabelecimento de contatos com os militantes brasileiros (JORNALISTAS..., 1931). Dois anos mais tarde, Tuñón foi contatado por Brasil Gerson, jornalista e ativo integrante da ANL, para alertá-lo a respeito da viagem de Vargas à Argentina, entendida como uma grande conspiração entre os governantes dos dois países. Neste sentido, o brasileiro escreveu ao argentino sugerindo "que ficasse atento, pois estava certo de que tudo isso era a preparação de um plano sinistro, que logo se efetivaria" (GERSON, 1935).

Ainda em 1935, Getúlio Vargas fez uma visita diplomática a Gabriel Terra no Uruguai. A comitiva do presidente teve, entre seus integrantes, o jornalista Jorge Amado $^{5}$, que possivelmente enviou uma reportagem ao periódico A Manhã narrando o atentado sofrido por Terra na ocasião da recepção a Vargas; o jornalista, que não assinou a reportagem ${ }^{6}$, aproveitou a estadia no Uruguai para entrar em contato com a intelectualidade de oposição ao regime terrista com vistas a se inteirar da situação política daquele país. Esse contato também permitiu que os intelectuais uruguaios tivessem notícias dos "exilados da última revolução uruguaia." (AMADO, 1935). Entre os exilados estava o chefe nacionalista Basílio Muñoz e outros envolvidos na "Revolución de enero" daquele ano que haviam se refugiado, em grande parte, no Rio de Janeiro (AGUIRRE GONZÁLEZ, 1985, p. 123-124).

Ainda no que se refere aos contatos entre intelectuais antifascistas do Cone Sul, cabe destacar a visita que o intelectual argentino Bernardo Kordon fez ao Brasil em 1937, analisada por Adrián Celentano (2010). Além de visitar a Bahia, teve encontros com intelectuais brasileiros. Ao retornar a Buenos Aires, Kordon expôs reflexões importantes sobre a cultura negra da região e passou a colaborar como correspondente na revista Cultura, mensário democrático (KORDON, 1939, p. 18).

\section{Exílio antifascista no Prata}

\footnotetext{
${ }^{5}$ Esta informação foi retirada do currículo de Jorge Amado presente no sítio da Academia Brasileira de Letras. Disponível em: http://www.academia.org.br/abl/cgi/cgilua.exe/sys/start.htm?infoid=727\&sid=244 Acesso em: 14/02/2013.

${ }^{6}$ Infere-se que o autor da reportagem é Jorge Amado, pois as informações coincidem: ele efetivamente acompanhou a comitiva do presidente Vargas ao Uruguai e colaborava frequentemente no jornal A Manhã.
} 
Os intercâmbios entre a intelectualidade antifascista do Cone Sul foram mais significativos a partir do grande afluxo de brasileiros que se exilaram na Argentina e Uruguai. Desde o início da década de 1930, brasileiros já vinham solicitando refúgio nesses países (RANGEL, 2002), mas a lista se ampliou muito a partir de $1935 .{ }^{7}$ Grande parte dos exilados chegou entre novembro de 1935 e início de 1936. Mas, Newton Freitas exilou-se somente após o golpe de 1937, após sair da prisão e Brasil Gerson, em 1939, após ter sido condenado pelo Tribunal de Segurança Nacional (TSN) pela participação na Aliança Nacional Libertadora (ANL). ${ }^{8}$

Entre os exilados, destaca-se o escritor e jornalista José Barboza Mello, refugiado em Buenos Aires desde o início da década. Ele teve uma trajetória intelectual e política bastante peculiar, sendo mais reconhecido nos países do Prata do que no Brasil. ${ }^{9}$ Segundo um esboço de biografia encontrado nos arquivos da Associação Brasileira da Imprensa (ABI), o escritor fora "deportado para o Uruguai por opor-se à revolução de 30," (MELLO, 19?) ainda no ano de 1931. Desde então, passou a escrever na imprensa platina. Com a criação da ANL, em fins de 1934, tornou-se porta-voz dessa associação na região do Prata, desempenhando um papel fundamental no que se refere à circulação de ideias.

Barboza Mello era um comunista ${ }^{10}$, mas não colaborou nos jornais e revistas dos partidos comunistas da região, nem na imprensa criada pela IC para a difusão das orientações soviéticas; também não colaborou na imprensa antifascista brasileira. Sua

\footnotetext{
${ }^{7} \mathrm{O}$ relatório da polícia política apresenta os seguintes nomes (sem se referir à data) como "exilados comunistas" no Uruguai: Roberto Sisson, Carlos da Costa Leite, José Gay da Cunha, Antonio Bento Monteiro Tourinho, Carlos B. França, Walter B. Silva, José Correia de Sá, David Capistrano, Jorge Amado, Pedro Mota Lima, Brasil Gerson, Ivan Martins, Luiz Cuneo, Abelardo Araujo, Vivaldo Vanjão, Telmo França, Armando Cunha, José Oliveira Andrade, Manoel Palheiro, H. Chester, Michel Reicher, Alberto Soriano Thebas, W. Feldman, Mary Mercio, Rosa Meireles, Gilberto Tourinho. A lista de refugiados é enorme e provavelmente não é possível de ser recuperada na íntegra. (DESPS, s.d.b., p. 232.)

${ }^{8}$ Brasil Gerson, jornalista do A Platéa e militante da ANL em São Paulo e Newton Freitas, militante da mesma organização no Rio de Janeiro, não serão analisados neste estudo.

${ }^{9}$ Daí a imensa dificuldade em se descobrir mais informações sobre a trajetória de José Barboza Mello (ou de Melo, ou Barbosa Melo). Seu prontuário (n. 9206 - DESPS-APERJ) apontava uma prisão no dia seguinte ao golpe de 1964. Nos arquivos da polícia política em São Paulo sua ficha indica ser "ele uma figura destacada nos meios extremistas da esquerda, mas toda sua atuação se tem feito sentir no Exterior. Em 1936, promoveu tenaz campanha de descrédito contra o Brasil nos países latinos (sic), digo, nos países platinos e foi autor de vários protestos contra as prisões dos 'lideres vermelhos"”. Cf. Prontuário n. 6079 José Barboza de Mello - DEOPS/SP - APESP.

${ }^{10}$ Duas entrevistas com atores que conheciam José Barboza Mello confirmam que ele era um "homem do partido". Entrevista com Luis Viegas da Mota Lima, 15/08/2012, Rio de Janeiro; Entrevista com Anita Leocádia Prestes, por email, em 05/06/2012.
}

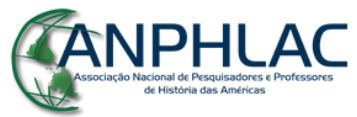

Revista Eletrônica da ANPHLAC, ISSN 1679-1061, №. 19, p. 25-42, jul./dez., 2015. http://revista.anphlac.org.br 
atuação esteve restrita ao universo dos intelectuais e militantes das Agrupaciones de Intelectuales, Artistas, Periodistas y Escritores (AIAPE) dos países do Prata. O escritor brasileiro contribuiu para a fundação da Confederación de Trabajadores Intelectuales de Uruguay (CTIU) no Uruguai e da AIAPE argentina; na primeira, foi secretário da publicação Movimiento. Mudou-se para a Argentina por ocasião da visita de Vargas ao Uruguai (MELLO, 19?), país onde viveu até início dos anos 40. Foi ativo colaborador do periódico argentino Unidad e ministrou algumas conferências na sede da AIAPE (VIDA..., 1937) e no Colegio Libre de Estudios Superiores MELLO, 1971?, p. 13). Graças a seus contatos na Argentina, foi importante elo entre as associações antifascistas, já que era conhecido entre os intelectuais do Prata como membro da ANL brasileira (GUILLOT MUÑOZ, 1937, p. 14).

A presença de Barboza Mello na AIAPE argentina explica algumas trocas importantes ocorridas entre os intelectuais da ANL e esta associação. Em Unidad aparece um artigo de Carlos Lacerda ${ }^{11}$, publicado anteriormente em Movimento, revista do Clube de Cultura Moderna. O texto, Cultura y Revolución, é um exemplo da interpretação marxista sectária sobre a cultura, apresentada como uma "arma de classe" da burguesia que deveria ser inevitavelmente transformada pela ascensão do proletariado (LACERDA, 1935, p. 6-7 e LACERDA, 1936, p. 5). Traduzido para o espanhol, o artigo de Lacerda foi a única reflexão teórica elaborada por brasileiros que repercutiu na imprensa antifascista argentina; o fato de ser expressão do radicalismo dos comunistas diz algo sobre o radicalismo das duas associações. No movimento contrário, um artigo de Nydia Lamarque, integrante da AIAPE argentina, sobre o centenário de Esteban Echeverría, publicado originalmente em Unidad, tem alguns trechos reproduzidos na Revista Acadêmica (LAMARQUE, 1937, p 6-7 e DE ESTEBAN, 1937).

O já referido relatório policial demonstrava a inquietação da repressão em relação ao papel cumprido por José Barboza Mello nas relações entre os "comunistas" brasileiros e rio-platenses. A polícia afirmava que ele servia de tradutor dos artigos que transitavam pelas fronteiras entre o periódico A Manhã, da ANL, e a CTIU, como se lê no trecho que segue:

${ }^{11}$ Carlos Lacerda foi militante do PCB até 1939; tornou-se posteriormente um opositor ferrenho do comunismo.

\section{BANPHLAC}

Revista Eletrônica da ANPHLAC, ISSN 1679-1061, №. 19, p. 25-42, jul./dez., 2015. http://revista.anphlac.org.br 
A Confederación de Trabajadores Intelectuales de Uruguay (CTIU) fornecia material para propaganda do jornal "A MANHÃ", do Rio de Janeiro. O Serviço de correspondência é feito por intermédio de Caixas Postais, pelas fronteiras e muitas vezes por navios do Lloyd Brasileiro. A tradução é feita por JOSÉ BARBOZA MELLO, atualmente em Buenos Aires. (DESPS, s.d.a, p. 14)

Além de tradutor, Barboza Mello elaborou e publicou dezenas de artigos na imprensa argentina e uruguaia entre 1933 e 1939. No levantamento dessas fontes foram encontrados, na imprensa argentina, textos publicados em Claridad, Contra-fascismo, Izquierda: crítica y acción socialista e Unidad, por la defensa de la cultura. No Uruguai, colaborou nos diários Acción e Movimiento. Na maioria dos artigos, abordava a situação política brasileira, com efetivo destaque para os objetivos e atuação da ANL.

Neste artigo, serão destacados somente os textos do escritor no boletim Unidad. Chama à atenção o fato de que, das seis edições da publicação, em três delas foram encontrados artigos de Barboza Mello. No primeiro número, o artigo "La bandera libertadora flamea en el sertão", expôs a conjuntura de miséria e exploração do estado do Rio Grande do Norte, fato que, segundo o autor, teria favorecido a "maduración de la conciencia de clase de las masas, de la idea de asalto al poder". O texto apresenta uma análise "otimista" da atuação da ANL naquele momento, pois anuncia "la victoria inminente de los que luchamos por la liberación de Brasil" (MELLO, 1936a, p. 7). Na edição seguinte, apresentou um panorama da produção cafeeira no país, abordando o papel do imperialismo e da oligarquia na exploração da população rural (MELLO, 1936b, p. 19). Por fim, já em 1937, publicou um texto de exaltação à candidatura do escritor José Américo de Almeida à presidência do Brasil, considerada, segundo o autor, praticamente vitoriosa, "porque cuenta con el imprescindible apoyo de la opinión popular". O texto dizia ainda que, "Después de Sarmiento, es la primera vez que se repite el fenómeno, en nuestra América, de que un escritor ocupe la suprema magistratura de la nación" (MELLO, 1937, p. 9).

Este último artigo desencadeou um posicionamento da AIAPE argentina em solidariedade à candidatura de José Américo: uma correspondência foi enviada ao escritor brasileiro que, segundo carta reproduzida em Unidad, "encarna las aspiraciones de los defensores de la cultura, el patrimonio mayor de la humanidad."( VIDA DE LA AIAPE,

\section{GANPHLAC}

Revista Eletrônica da ANPHLAC, ISSN 1679-1061, №. 19, p. 25-42, jul./dez., 2015. http://revista.anphlac.org.br 
1937, p. 12) Libório Justo, naquele momento já próximo dos trotskistas, das páginas do La Nación, teceu duras críticas ao apoio da AIAPE à candidatura do escritor, comparando-o com Roberto Ortiz, candidato a presidente da Argentina naquele momento, julgando-o representante da oligarquia brasileira, bem como "agente descarado del imperialismo yanqui”" (TROISE, 1937). Emilio Troise, presidente da AIAPE, respondeu às críticas afirmando conhecer a complexidade da situação do país, ponderando que "callar o censurar en abstracto, hubiese sido lo más cómodo, o una de las tantas maneras elegantes e inofensivas de permanecer al margen del drama que vive el país vecino" (TROISE, 1937). No momento da resposta de Emilio Troise, o Brasil já havia mergulhado na ditadura do Estado Novo e as previsões de Barboza Mello sobre a vitória iminente de José Américo foram frustradas.

No Uruguai, as contribuições de Barboza Mello ocorreram nas atividades do CTIU, a partir da publicação de textos de divulgação sobre a ANL (MELLO, 1935, p. 10). Após o surgimento da AIAPE no país, não se encontrou mais nenhuma referência à participação do escritor até o Congresso Internacional das Democracias, em março de 1939.

O engajamento de Barboza Mello na luta contra o fascismo foi além das atividades na imprensa. Em conjunto com o jornalista comunista Pedro Mota Lima, também exilado na Argentina, o escritor publicou a obra El nazismo en el Brasil. Proceso del estado corporativo, em 1938, pela Editorial Claridad. Trata-se de um longo relato jornalístico da situação política brasileira dos anos 1920 e 1930, no qual os autores buscaram esclarecer as forças políticas em conflito e fundamentar a tese da influência nazista no governo de Getúlio Vargas, sobretudo após o golpe de novembro de 1937. No prólogo da obra, a cargo de Mario Bravo, senador pelo Partido Socialista Argentino, é possível notar a existência de certa reserva em relação ao Brasil por parte do público leitor da região. Justificando a diferença entre lutar contra o imperialismo brasileiro na região do Prata e a favor do povo deste país, Bravo recuperou as disputas anteriores em que o Brasil e a Argentina estiveram de lados opostos na tentativa de situar a luta antifascista em curso naquele momento como uma questão de solidariedade entre os povos e não entre impérios:

\section{GANPHLAC}

Revista Eletrônica da ANPHLAC, ISSN 1679-1061, №. 19, p. 25-42, jul./dez., 2015. http://revista.anphlac.org.br 


\begin{abstract}
Alberdi sempre montou guarda na fronteira argentina, como medida de precaução. Contra o Brasil? Não. Contra o Império. Contra o estado político e social que era representado pelo Império. Éramos uma república recém liberta de uma tirania e necessitávamos, para o fortalecimento das instituições democráticas de fundo e de forma, estarmos cercados de países de mesma densidade e com interesses coincidentes. A monarquia era uma vizinha ruim, com a escravidão como constituição legal e com comércio, com a abolição da liberdade, com o esmagamento ímpio de toda tentativa de emancipação. Mas Alberdi estava com o povo do Brasil. Foi seu agitador, na medida em que pode. ${ }^{12}$ (BRAVO, 1938, p. 5)
\end{abstract}

A virulência dos ataques a Getúlio Vargas no corpo do livro sofre uma alteração repentina no último capítulo, pois o golpe integralista de maio de 1938 surpreendeu os autores, que produziam a obra "de un plumazo, en medio del tumulto de la labor cotidiana en la redacción de los diarios porteños" (LIMA; MELLO, 1938, p. 216). Na parte final do livro, o apoio a Vargas contra o fascismo foi insinuado, devido à recente adoção da estratégia de União Nacional. Esta ambiguidade pode ter contribuído para que a obra de José Barboza Mello e Pedro Mota Lima não tivesse obtido ressonância nem nos países do Prata, nem no Brasil. O livro não foi o único lançado sobre o tema no período; obteve maior destaque a obra Penetración Nazi en América, de Adolfo Tejera, lançado também em 1938 pela Editorial Nueva América, de Montevidéu; o livro foi resenhado uma dezena de vezes nos periódicos envolvidos na luta antifascista.

Esta última editora, criada pelo intelectual batllista ${ }^{13}$ e membro destacado da AIAPE uruguaia, Justino Zavala Muniz também foi responsável pela tradução e publicação de um livro de Mota Lima no Uruguai em 1937. O projeto editorial teve início com a obra Bruhaha (1927). Segundo Zavala Muniz, a editora tinha um caráter americanista:

Su denominación indica ya, que intentaremos hacer de nuestra editorial una tribuna del pensamiento contemporáneo americano, y de aquellos que, venidos de Europa, consideremos útiles y necesarios para orientación de la cultura de

\footnotetext{
12 “Alberdi, siempre montó guardia en la frontera argentina, en medida precautoria. ¿Contra el Brasil? No. Contra el Imperio. Contra el estado político y social que tenía por exponente el Imperio. Éramos una república recién liberada de una tiranía y necesitaba, para el arraigo de las instituciones democráticas de fondo y de forma, rodearse de países de su misma densidad y de coincidentes intereses. La monarquía era una mala vecina, con la esclavitud como constitución legal y comercio, con la abolición de la libertad, con el aplastamiento impío de toda tentativa hacia la emancipación. Pero Alberdi estaba con el pueblo del Brasil. Fue su agitador, en la medida que pudo." Traduzido pela autora.

${ }^{13}$ Batllismo é a uma corrente política do Partido Colorado no Uruguai que denomina os seguidores do presidente José Batlle y Ordoñez.
}

\title{
GANPHLAC
}

Revista Eletrônica da ANPHLAC, ISSN 1679-1061, № 19, p. 25-42, jul./dez., 2015. http://revista.anphlac.org.br 
estos pueblos. No tendremos pues, ni fronteras territoriales, ni estéticas, ni mentales. (CRÍTICA..., 1937, p. 9)

A crítica feita ao livro de Mota Lima nas páginas do boletim da AIAPE uruguaia, assinada pelo poeta Cipriano Santiago Vitureira, mostra a importância que se dava ao conhecimento de outras realidades para a compreensão dos problemas do Uruguai. Mesmo julgando a obra como "fruto de la conciencia esquemática de una época", Santiago Vitureira afirmou que o livro "logra medir nuestros propios problemas, [por medio de] la visión de ellos en climas diferentes.” (CRÍTICA..., 1937, p. 9)

Para além desta atuação literária, houve colaborações de Pedro Mota Lima na imprensa do Prata. Ainda que modestas, estas também preocuparam a polícia política. Em outro informe encontrou-se a acusação ao jornalista de, por meio de artigos, estremecer as relações cordiais do Brasil com outros povos sul-americanos:

Vê-se claramente que Mota Lima, a serviço da propaganda dissolvente do partido comunista, não só deseja lançar o povo do Brasil contra o seu grande benfeitor que é o Presidente Vargas, como também se propõe a aguçar a antipatia de outros povos contra as diretrizes do Estado Novo. (DESPS, 1938, p. 7-32)

O menor envolvimento de Mota Lima com a imprensa antifascista talvez se explique pelo fato de ele ter retornado ao Brasil na clandestinidade e, mesmo assim, continuar publicando no Uruguai e na Argentina como forma de disfarce. ${ }^{14}$ Qualquer que tenha sido o motivo, Pedro Mota Lima teve menor contato com as AIAPEs do Prata, se compararmos com a atuação de José Barboza Mello.

Além de Mota Lima, diretor do diário frentista A Manhã, do Rio de Janeiro, Brasil Gerson, diretor do jornal A Platéa, de São Paulo, também buscou refúgio nos países do Prata. Gerson teve contato com a AIAPE uruguaia logo que chegou ao Uruguai em 1939. Seu nome aparece como novo associado (CON LA DEMOCRACIA..., 1939, p. 8) e como tendo recebido ajuda da associação (UN AÑO..., 1939, p. 20). Não foram encontradas contribuições do jornalista na imprensa antifascista; ele trabalhou para o jornal La Razón, que não fez parte das fontes da pesquisa que deu origem a este artigo.

\footnotetext{
${ }^{14}$ Em entrevista com a autora, Luis Viegas da Mota Lima, filho de Pedro, afirma: "Para todos os efeitos [ele] estava exilado na Argentina, mas, por volta de 1937, me encontrava com ele todos os sábados [no Rio de Janeiro]". Entrevista concedida a autora, por telefone, em 20/04/2012.
}

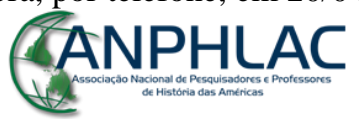

Revista Eletrônica da ANPHLAC, ISSN 1679-1061, №. 19, p. 25-42, jul./dez., 2015. http://revista.anphlac.org.br 
No final de 1939, Brasil Gerson escreveu uma carta "en nombre de los periodistas exiliados en el Plata" ao ministro Fernando Costa, pedindo que lhes fosse concedido, por Vargas, o perdão judicial, o que foi negado (DESPS, 1939, p. 53). Em 1942, frente ao posicionamento do Brasil ao lado dos aliados na Segunda Guerra Mundial, Brasil Gerson e Mota Lima retornaram ao Brasil, quando são presos por cerca de dois anos até a anistia assinada por Vargas em junho de 1944.

A intensa divulgação das atividades da ALN nos países do Prata acabou fazendo crer que a organização tinha maior amplitude do que realmente possuía entre 1936 e 1937. Após a repressão a organização havia sido desmantelada e somente alguns militantes do PCB se mantiveram na ativa.

Interceptada pela polícia, uma correspondência de um militante exilado em Montevidéu para os companheiros de partido que permaneciam no Brasil explicita a ação de propaganda realizada pelos militantes comunistas junto à intelectualidade e aos periódicos da Argentina e do Uruguai. ${ }^{15}$ Um trecho dessa correspondência evidencia o trânsito de materiais, tanto enviados de Montevidéu, quanto do Brasil:

Tenho lhes enviado todo o material possível, no limite das possibilidades dos portadores. Há menos de uma semana, partiu daqui uma boa quantidade. O homem, que já levou uma vez, desta estava com medo. Não sei se chegará. [...] De todo material que enviarem, mandem sempre dois exemplares, pelo menos: um para cá, outro para Bs.As. Isto me poupa o trabalho de multiplicar aqui e mais depressa é publicado lá. (DESPS, 1936, p. 1)

Os materiais chegados do Brasil serviam para fornecer informações e pautar a imprensa com relação, principalmente, à questão dos presos políticos, centrada nas figuras de Luiz Carlos Prestes e Rodolfo Ghioldi. Para tal, havia uma circulação do boletim brasileiro $O$ Libertador, levado a Montevidéu, que servia para alimentar informações para os periódicos platenses. ${ }^{16}$ Esta ação de propaganda explica a profusão

\footnotetext{
${ }^{15}$ Não foi possível identificar os pseudônimos utilizados na correspondência.

${ }^{16}$ Como mostra o seguinte trecho do documento: "O Boletim Semanal do S.V., sul americano, transcreveu todos os discursos do CHERMONT, assim como 'Amnistia'. Igualmente tem sido lidos nos atos públicos e referidos em discursos de nosso pessoal. De certos materiais, como 'O Libertador' e 'Sentinela Vermelha', de que eu muito necessito para o trabalho [...] podem mandar maior número, não só porque é difícil multiplicar, como serve para mandar para o Rio Grande.” (DESPS, 1936, p. 1).
}

\section{GANPHLAC}

Revista Eletrônica da ANPHLAC, ISSN 1679-1061, №. 19, p. 25-42, jul./dez., 2015. http://revista.anphlac.org.br 
de artigos sobre a vida de Luiz Carlos Prestes e expressões de solidariedade a sua trajetória política.

A campanha pela libertação dos presos esteve oficialmente a cargo do Socorro Vermelho Internacional (SVI), organização ligada à III Internacional, responsável pela ajuda a presos políticos e seus familiares. Mesmo assim, na Argentina e no Uruguai, a mobilização em torno do tema foi intensa, encontrando espaços na agenda de militantes de diferentes tendências e alcançando, inclusive, uma grande repercussão popular. Para além da atuação na imprensa, houve mobilizações de protesto e arrecadação de fundos, que também inquietaram a polícia brasileira. Na referida carta, o militante brasileiro afirmava: “a massa aqui é um fato.” (DESPS, 1936, p. 1)

A propósito dos movimentos de solidariedade a Luiz Carlos Prestes, foi dedicado um relatório policial elaborado pelo temido chefe da Seção de Segurança Social, Seraphim Braga. O relatório se baseava em recortes de jornais e revistas coletados em diversos países, que serviram para reconstituir, detalhadamente, os eventos e os envolvidos na campanha pela libertação de Prestes. Como afirma Maria Luiza Tucci Carneiro (2006, p. 155), no discurso da polícia política, a imprensa tinha o status de evidência. Seraphim Braga responsabilizou, principalmente, aos intelectuais pela "fama de Luiz Carlos Prestes ter cruzado as fronteiras” (DESPS, s.d.b., p. 275-280).

A referida campanha envolveu grupos de intelectuais nos Estados Unidos, México, Cuba, Bolívia, Argentina, Chile e Uruguai. De modo geral, a campanha se restringia a moções de repúdio assinadas por intelectuais e tornadas públicas através de periódicos ou telegramas dirigidos ao presidente Vargas solicitando a libertação do preso. Algumas petições foram endossadas pelo Poder Legislativo de alguns desses países, como foi o caso de Cuba. A intenção era utilizar o prestígio intelectual ou político de estrangeiros para pressionar o governo brasileiro e, ao mesmo tempo, tornar pública a trajetória do prisioneiro, reverenciado como "libertador do povo da América".

No Uruguai, em uma sessão do Comitê de ajuda ao Povo Espanhol, em 1936, a moção aprovada exigia do governo brasileiro a liberdade do "glorioso lutador pela liberdade de seu povo e guia para todos os povos do continente, General Luiz Carlos Prestes." Nesse país, assim como na Argentina, os comitês a favor da liberdade de Prestes confeccionaram cartões com a fotografia do militante para, com a venda, arrecadar

\section{GANPHLAC}

Revista Eletrônica da ANPHLAC, ISSN 1679-1061, №. 19, p. 25-42, jul./dez., 2015. http://revista.anphlac.org.br 
fundos; os relatórios policiais afirmam que tais publicações teriam alcançado a cifra de 10.000 exemplares. (DESPS, s.d.b., p. 275-280).

$\mathrm{Na}$ Argentina também funcionava o Comitê de Anistia aos Presos e Exilados Políticos da América, sob a responsabilidade dos congressistas Mario Bravo e Lisandro de la Torre. Segundo Vecchioli (2007), esta, entre outras organizações "en defensa de las víctimas de la dictadura" funcionavam à parte de uma filiação partidária específica, ou seja, seus membros pertenciam tanto ao Partido Comunista como à União Cívica Radical ou ao Partido Socialista.

Em Montevidéu, o clamor em torno das manifestações contra o governo brasileiro, no caso Prestes, desencadeou a criação da lei nº 9565 , de junho de 1936, que passava a exigir autorização prévia para "toda reunión cuya finalidad se ala de hacer demostraciones o críticas, favorables o contrarias, a la política de un Estado extranjero" (PORRINI, 1994, p. 69). A referida lei foi posta em prática seguidas vezes para impedir concentrações políticas contrárias aos governos vizinhos.

A referida carta do militante brasileiro exilado traz um relato, entre maravilhado e emocionado, de uma das manifestações a favor das "víctimas de la represión brasileña” em 23 de maio de 1936. Entre a esperança e o desterro, a narrativa mostra qual era a perspectiva de seguir militando no exterior:

[...] A grande homenagem a Balthazar Brum, que se converteu, afinal, num ato monumental pela Frente Popular de apoios às vitórias francesa, espanhola e russa, e numa estrondosa manifestação de apoio à ANL, a Prestes e ao Brasil, isto é, ao seu povo. Quando Córdova Iturburu, do grupo de intelectuais argentinos e Eugenio Gomez, deputado do Partido Comunista Uruguaio se aproximavam, nos seus discursos, da situação americana, antes mesmo de chegarem ao Brasil, para onde se via que a oração se inclinava, já formidável massa, que enchia o Atheneu e os milhares que estamos na rua, sob a chuva, escutando nos alto-falantes, na parte térrea do edifício, começavam lentamente, a princípio em surdina, depois mais depressa e mais alto: "Prestes!...Prestes!...Prestes!...". O Firmo, velho sentimental, nesta noite, como no $1^{\circ}$ de maio, teve que esconder no lenço discretamente, um pouco de sua emoção e de sua saudade. (DESPS, 1936, p. 1)

A carta esclarece que o intercâmbio com os países do Prata manteve acesa a militância em prol da Frente Popular dos comunistas brasileiros, voltada agora para as realidades políticas dos países vizinhos.

\section{GANPHLAC}

Revista Eletrônica da ANPHLAC, ISSN 1679-1061, №. 19, p. 25-42, jul./dez., 2015. http://revista.anphlac.org.br 


\section{Conclusão}

Este artigo demonstrou que o intenso trânsito de intelectuais e impressos entre o Brasil, a Argentina e o Uruguai serviram para dinamizar a luta antifascista tanto no plano interno aos países quanto no âmbito internacional. Da mesma forma, os deslocamentos e as trocas realizadas no seio da luta antifascista serviram para reforçar o caráter transnacional do antifascismo, que possuía características locais e ao mesmo tempo globais.

Neste contexto, o exílio de intelectuais foi mais um elemento que favoreceu os intercâmbios políticos e culturais. Por meio das atividades de imprensa, da publicação de jornais e revistas, da inserção de reportagens e relatos nos meios impressos já existentes, da circulação de correspondências, da tradução e publicação de livros e da participação de atos públicos, estes intelectuais auxiliaram a fortalecer a luta contra os governos autoritários e contra o fascismo.

O exílio dos brasileiros nos países do Prata serviu ainda para a divulgação da situação política brasileira nos países vizinhos, ao intercâmbio cultural e à articulação de uma solidariedade aos presos políticos encarcerados naquele momento no Brasil. Ao colocar a situação brasileira em destaque, as pressões internacionais e a visibilidade da própria causa fizeram com que a Aliança Nacional Libertadora (ANL) parecesse estar mais atuante do que a dura realidade da repressão policial no país permitia.

\section{Referências bibliográficas}

AGUIRRE GONZÁLEZ, A. La revolución de 1935: la lucha armada contra la dictadura. Sin local, Librosur, 1985. 151p.

AMADO, Jorge. Montevidéu perante a ditadura sanguinária de Terra. A Manhã, Rio de Janeiro, ano 1, n. 41, p. 1, 12 jun. 1935.

AYÇAGUER, Ana María Rodríguez. La diplomacia del anticomunismo: la influencia del gobierno de Getúlio Vargas en la interrupción de las relaciones diplomáticas de Uruguay con la URSS en diciembre de 1935. Estudos Ibero-Americanos, Porto Alegre, v. XXXIV, n. 1, p. 92-120, junho 2008.

\section{GANPHLAC}

Revista Eletrônica da ANPHLAC, ISSN 1679-1061, №. 19, p. 25-42, jul./dez., 2015. http://revista.anphlac.org.br 
BRAVO, Mario. Prefácio. In: MOTA LIMA, Pedro; BARBOZA MELlO, José. El nazismo en el Brasil. Proceso del Estado corporativo. Buenos Aires: Editorial Claridad, 1938 , p. 5-18.

CARNEIRO, Maria Luiza Tucci. O lugar do impresso revolucionário: dos porões aos arquivos policiais. In: DUTRA, Eliana de Freitas; MOLLIER, Jean-Yves (Orgs.). Politica, Nação e Edição. O lugar dos impressos na construção da vida política. Brasil, Europa e Américas nos séculos XVIII-XX. São Paulo: Anablume, 2006, p. 153-179.

CON LA DEMOCRACIA y la cultura auténticas. AIAPE, por la defensa de la Cultura, Montevideo, año 4, n. 29, p. 8, oct/ dic, 1939.

CRÍTICA y Libros, AIAPE, por la defensa de la Cultura, Montevideo, año 1, n. 7, p. 9, jul. 1937.

DESPS. Dossiê Partido Comunista no Uruguai. Fundo Polícias Políticas, Setor Sulamericano, Notação 3 A, s.d.a, APERJ.

Pedro Mota Lima e seus incertos subversivos. Fundo Polícias Políticas, Setor Comunismo, Notação 11d, mai. 1938, APERJ. Os jornalistas brasileiros exilados pedem clemência. Fundo Polícias Políticas. Setor Comunismo, Notação 11d, ago. 1939, APERJ. Dossiê Partido Comunista no Uruguai (Carta de Montevidéu.) Fundo Polícias Políticas, Setor Sul-americano, Notação 3 A, 6 jun. 1936, APERJ. . Relatório sobre atividades comunistas. Fundo Polícias Políticas, Setor Comunismo, Notação 11 cont., s.d.b.,APERJ.

DE ESTEBAN, Echeverría. Revista Acadêmica, Rio de Janeiro, ano 4, n. 30, set. 1937.

DUTRA, Eliana de Freitas; MOLLIER, Jean-Yves (Orgs.). Politica, Nação e Edição. O lugar dos impressos na construção da vida política. Brasil, Europa e Américas nos séculos XVIII-XX. São Paulo: Anablume, 2006.

GERSON, Brasil. Sob a máscara da confraternização universal. A Manhã, Rio de Janeiro, ano 1, n. 27, p. 2, 26 mai. 1935.

GROPPO, Bruno. El antifascismo en la cultura política comunista. In: CONCHEIRO BORQUÉZ, E.; MODONESI, M.; CRESPO, H. El comunismo: otras miradas desde America Latina. Universidad Nacional Autónoma de Mexico. México, 2007, p. 93-118.

GUILLOT MUÑOZ, Gervasio. La intelectualidad antifascista en América: La AIAPE de Buenos Aires. AIAPE, por la defensa de la cultura, Montevideo, año 1, n. 3, p. 14, marzo 1937.

JORNALISTAS argentinos em visita à NOITE. A Noite, Rio de Janeiro, p. 4, 23 mai. 1931.

\section{GANPHLAC}

Revista Eletrônica da ANPHLAC, ISSN 1679-1061, №. 19, p. 25-42, jul./dez., 2015. http://revista.anphlac.org.br 
KORDON, Bernardo. A falange espanhola e a conquista da América por Hitler. Cultura, mensário democrático, Rio de Janeiro, ano 1, n. 9, p. 18, jul. 1939.

LACERDA, Carlos. Cultura e Revolução. Movimento, revista do Club de Cultura Moderna, Rio de Janeiro, ano 1, n. 3, p. 6-7, set. 1935.

. Cultura y Revolución. Unidad, por la defensa de la cultura, Buenos Aires, año 1, n. 3, p. 5, abr. 1936.

LAMARQUE, Nydia. Epítome a Esteban Echeverría. Unidad, por la defensa de la cultura, Buenos Aires, año 2, n. 1, p. 6-7, agosto 1937

MELlO, J. Barboza. La Alianza Nacional Libertadora del Brasil. Movimiento, Montevideo, año 3, n. 16, p. 10, sept. 1935.

La bandera libertadora flamea en el sertão. Unidad, por la defensa de la cultura. Buenos Aires, año 1, n. 1, p. 7, enero 1936a.

40 millones de bolsas de café. Unidad, por la defensa de la cultura, Buenos Aires, año 1, n. 2, p. 19, feb. 1936b.

La candidatura presidencial de un escritor popular. Unidad, por la defensa de la cultura, Buenos Aires, año 2, n. 1, p. 9, agosto 1937.

José Barboza Mello, sem local, manuscrito, 19?, 4p.

Historia das lutas do povo brasileiro. Marcha de 4 séculos pela emancipação do país. Rio de Janeiro: Editora Leitura, s/d [1971?].

MOTA LIMA, Pedro; BARBOZA MELLO, José. El nazismo en el Brasil. Proceso del Estado corporativo. Buenos Aires: Editorial Claridad, 1938.

OLIVEIRA, Ângela Meirelles de. Intelectuais antifascistas no Cone Sul: experiências associativas entre a cultura e a política. Projeto História (PUCSP), v. 47, p. 1-31, 2013.

O papel da imprensa na circulação de ideias e de intelectuais antifascistas entre a Argentina, Uruguai e a França (1933-1939). Faces da História, v. 2, p. 159-171, 2015.

OLIVEIRA, Luís Eduardo Prado de. Du fonctionnement psychique de l'étranger. Dialogue - recherches cliniques et sociologiques sur le couple et la famille, 1991, $3^{\circ}$ trimestre.

PORRINI, Rodolfo. Derechos Humanos y dictadura terrista. Montevidéu: Vintén Editor, 1994.

RANGEL, Carlos Roberto do R. A conspiração revolucionária da oposição brasileira a Vargas no Prata (1930-1934). Revista Eletrônica da Anphlac, n. 2, p. 3-28, 2002.

ROLLEMBERG, Denise. Exilio: entre raízes e radares. Rio de Janeiro: Record, 1999. $375 p$.

SZNAJDER Mario; RONIGER Luis. The Politics of Exile in Latin America. NY: Cambridge University Press, 2009. 368p.

\section{GANPHLAC}

Revista Eletrônica da ANPHLAC, ISSN 1679-1061, №. 19, p. 25-42, jul./dez., 2015. http://revista.anphlac.org.br 
TERONI, Sandra; KLEIN, Wolfgang. Pour la défense de la culture: les textes du Congrès international des écrivains (Paris, juin, 1935), Dijon: Editions Universitaires de Dijon, 2005.

TROISE, Emilio. Carta abierta a Liborio Justo. Claridad, Buenos Aires, n. 320, dic. 1937.

UN AÑO de extraordinaria labor de la AIAPE. AIAPE, por la defensa de la Cultura, Montevideo, año 4, n. 29, p. 20, oct/dic, 1939.

VECCHIOLI, Virginia. La invención de la causa por los derechos humanos en la Argentina. PRIMERAS JORNADAS DE ESTUDIOS SOBRE COMPROMISO MILITANTE Y PARTICIPACIÓN POLÍTICA, Olavarría, 2007. Anais... Olavarría, 2007, p. 1-23. Disponible en: http://historiapolitica.com/compromiso/. Acceso en: 13 jun. 2012.

VIDA DE LA AIAPE. Unidad, por la defensa de la cultura, Buenos Aires, año 2, n. 2, p. 12 , sept. 1937.

\section{GANPHLAC}

Revista Eletrônica da ANPHLAC, ISSN 1679-1061, №. 19, p. 25-42, jul./dez., 2015.

http://revista.anphlac.org.br 